\title{
Learning Model: A Theoretical Framework
}

\author{
Abdul Hameed ${ }^{1}$, Dr. Abou Bakar ${ }^{2}$ \\ ${ }^{1}$ Assistant Professor of Management Sciences, The Islamia University of Bahawalpur, Bahawalnagar \\ Campus. \\ ${ }^{2}$ Director Campus/ Assistant Professor of Management Sciences, The Islamia University of \\ Bahawalpur, Bahawalnagar Campus.
}

\begin{abstract}
Learning is a core concept of HRD. Learning is also an emerging topic of knowledge transferring and knowledge management for improving the organizational performance. Therefore, organizations are investing huge amount of money on employee learning and development. This paper analyzes the theoretical framework \& models related to employee learning and organizational learning in order to improve the performance. The key variables identifies related to employee learning. There are so many learning models are developed by $H R D$ researchers' e.g. Carroll's learning model, Kolb, Mayer, Lave, Gibson, and Burner's learning model etc. The further discussion develops a proposed learning model which explains the key variables (Aptitude, Attention, Air pressure, learning from others, Feedback etc).The paper is divided into three parts. The introductory part provides brief overview related to learning and affect on performance. The second part analyzes the views and studies of the past researchers related to Learning models. In the end, paper presents the proposed model along with the discussion and conclusion.
\end{abstract}

Keywords: Learning \& development, learning model, organizational performance.

\section{Introduction}

Learning is the core concept of the HRD. The learning Phenomena initially gained popularity when people were motivated to learn from the environment (learn from experience, observations) to enhance their knowledge which was acknowledged by the outcomes in terms of skill and concept development (Fenwick, 2001). Now a day's HRD experts focus on learning as one of the key techniques to improving performance (Swanson \& Holton, 2009). Models of learning focus on what learners do? How to learn and what are the methods and process to learn? There are so many learning models are developed by HRD researchers' e.g. Carroll's learning model, Kolb, Mayer, Lave. Gibson, and Burner's learning model etc. 
Firstly paper will present the previous researchers learning models and then self made proposed learning model in the light of literature review.

\section{Carroll's Model of School Learning}

On the behalf of model of learning given by Carroll's Model of school learning; there are five attributes that can tribute to the effectiveness of learning.

- Aptitude

- Ability to understand instructions

- Preservance

- Opportunity

- Quality of Instruction

The eight phases of learning based on (Gagne 1985)

- Attention

- Expectancy

- Retrieval to working memory

- Selective perception

- Encoding (Entry information in long storage)

- Responding

- Feedback

- Cueing Retrieval (applying information that has already being learned)

\section{Learning from Feedback}

Feedback is a central to learning. In absence of the knowledge of the results, it is not an appropriate strategy to learn. In Thorndike's (1931) classical conditioning theory, feedback strengthens stimulus-response connections by functioning as either a reward or a punishment. Feedback is also central to Skinner's (1969) more contemporary operant conditioning theory, in which behavior is shaped by its consequences.

Christopher (2004) reveals four key phases: identifying, integrating, searching, and implementing. Each of these phases can provide opportunities to reflect on new information and thereby allow organization members to make a creative mental leap to a new theory of action. 


\section{Figure 1}

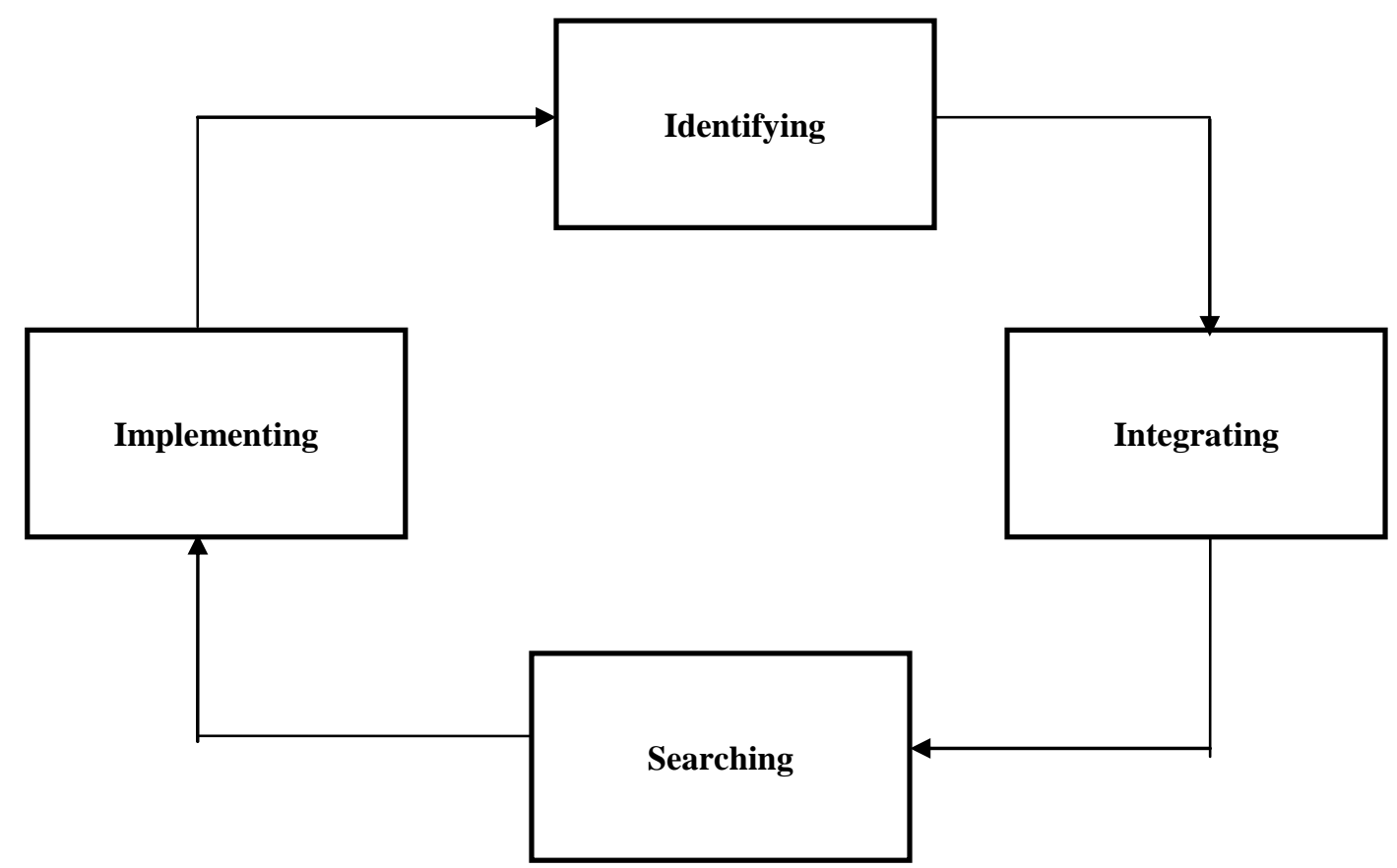

Source: Christopher Mausolef (2004), Learning From Feedback in Performance Measurement Public Performance \& Management Review Volume 28, Number 1 pp. 9-29.

\section{A. Air Pressure}

Understanding invisible and abstract attributes because air experts pressure and is made up of tiny particles (molecules) that are constantly moving (invisible process attributes). For air pressure, Student needs to understand the air particles (invisible attribute) exists pressure on all of sides of the system, including whatever is invisible system (Hsiao-Ching 2005). The more one pushes the system, the more air particles push again whatever is inside the system.

\section{B. Organizational Learning}

Chay Hoon (2003) Organizational learning refers the acquisition of knowledge. It means to acquire competitive information or knowledge e.g. customer survey, research and developemental activity. It also includes congenial learning (gathering information and interpretation). 


\section{Figure 2}

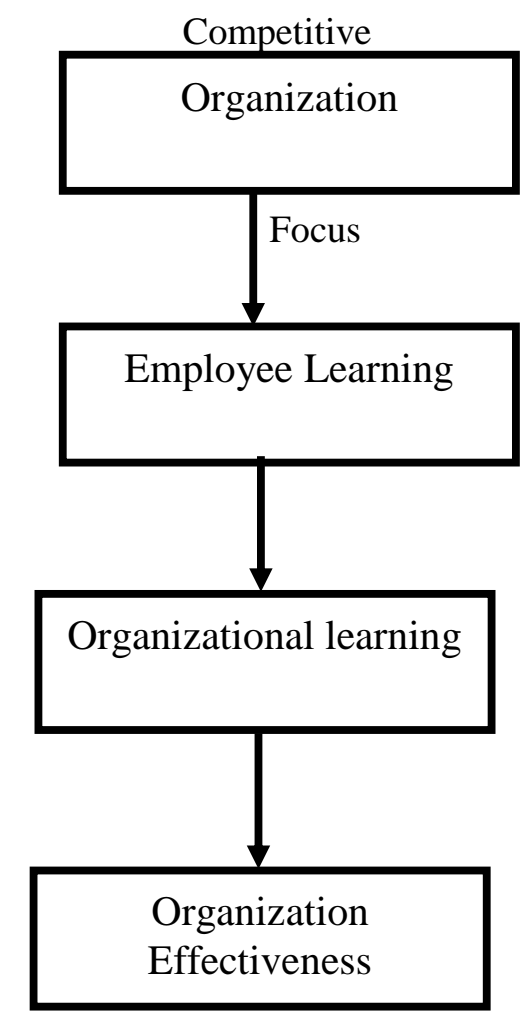

Source: Chay Hoon Lee and Norman T. Bruvold, (2003). 'Creating value for employees: investment in employee development, Int. J. of Human Resource Management Vol.14 No. 6 p 981-1000.

\section{Learning Process}

It includes learning by doing, learning by feedback, and learning by experience. Learning by doing means to accumulate knowledge and information by doing own self Gibbs G (1988). Learning by feedback refers to learning from knowledge of results. Learning by experience describes to learn from mistakes and involve practically.

- Drawing knowledge from available organizations environment

- Learning by experience

- Learning by observing other organizations

- Grafting on to self components that possessed by knowledge.

Three basic aspects of learning (Adrianus 2004).

- Knowledge of learning content

- Attitude towards learning process

- Aptitude 


\section{Emergent Model of Strategic Learning}

Strategic learning is the core issue of knowledge management. Strategic learning consist of six steps i.e. aptitude, knowledge of learning content, attitude towards learning process, attention, learning from others and multimedia technologies (James B. Thomas 2001).

- Aptitude

- Knowledge of learning content

- Attitude towards learning process

- Attention

- Learning from others

- Multimedia Technologies

Figure 3

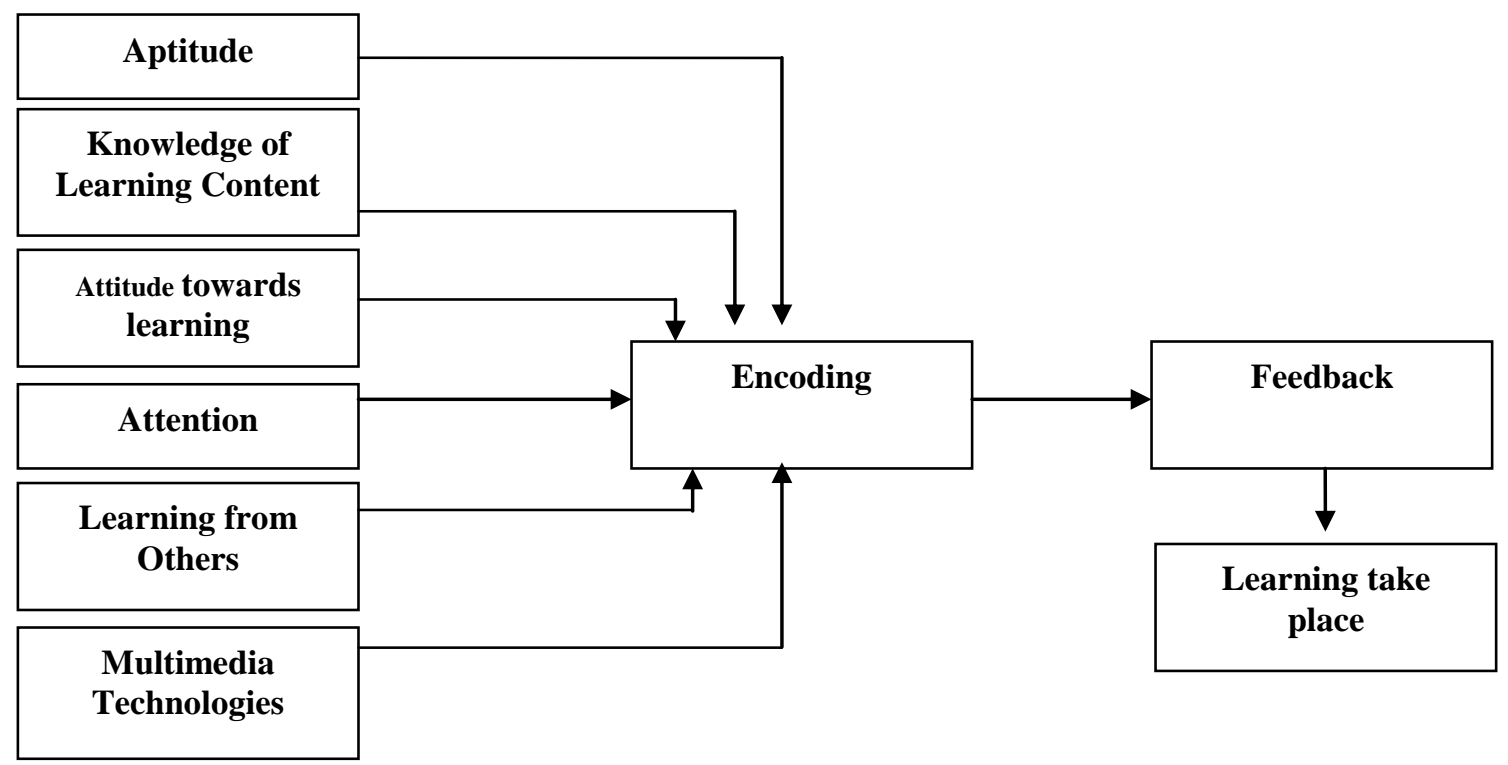

Source: James B. Thomas (2001) Understanding Strategic learning: linking in organizational learning, knowledge management. Vol.12 No. 3 Pp. 331-345

\section{A. Step 1 Aptitude}

It refers to the student general abilities to learn. This is an important component of learning model. Learning cannot take place without the aptitude factor. As when the individual has an ability to learn, he will be able to learn what he wants to learn. For example learning a computer skill required the student aptitude to learn i.e. student is able to learn 
should have some knowledge or ability to learn that thing should have computer handling skills.

\section{B. Step 2: Knowledge of learning content}

The knowledge of learning content is important. The students or individual must have some information about learning material; he is being able to learn the knowledge of relevant facts and principles about to learn.

\section{Step 3: Attitude towards learning process}

Attitude towards the learning process include one's willing to attempt to understand a specific matter. If a person is willing to understand a particular thing then learning would take place effectively and efficiently otherwise not (Dixon, N. M., 1999).

\section{Step 4: Attention}

The learner must have attention during the learning session. It refers to the active listening of the learner or student which will lead to grasp the lecture, dictation or learning material.

\section{E. Step 5: Learning from others}

Learning from other members depends upon the following two main factors:

- The level of communication adopted.

- Other's willingness to provide information.

The learning from others effect is mostly carried out through formal or informal communication among members of the same or different organizations (Deweett and Tons 2001).

\section{F. Step 6: Multimedia Technologies}

In order to deliver the learning material, the learning content should be delivered through or by multimedia technologies. The learning material can be stored in CD's, Tape, in order to make learning more effective.

\section{Encoding}

This lead to the storage of the information for the long period of time, these make the learning more effective.

\section{Feedback}

Feedback is central to learning. Without knowledge of results, is not an effective learning strategy (Thorndike 1931). Feedback is central to more contemporary apparent conditioning theory in which behavior is shaped by its consequences. 


\section{Proposed Model (Self made)}

The propose model is devise in the light of literature review of past researchers conducted in different studies related to learning models. The propose model is self made and explains the relationship between employee development and employee performance. Employee performance is a dependent variable and Employee development is independent variable. Employee development variable is operationalized by the following sub variables;

Figure 4: Proposed Learning Model: Learning from Feedback and Its components

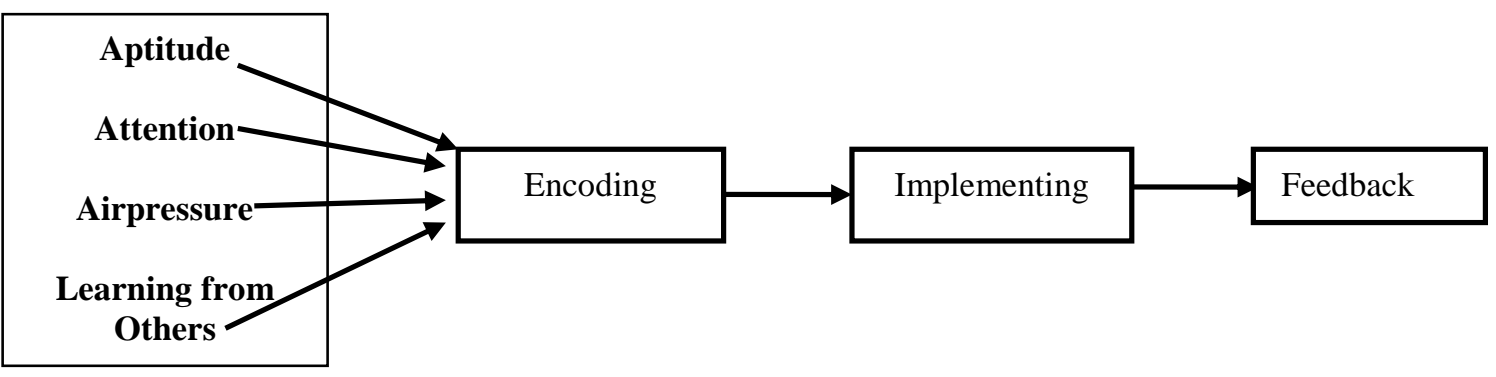

\section{Part 1: Aptitude}

The person or individual should have an aptitude towards learning. It refers to the student general abilities to learn. This is an important component of learning model. Learning cannot take place without the aptitude factor. As when the individual has an ability to learn, he will be able to learn what he wants to learn. For example learning a computer skill required the student aptitude to learn i.e. student is able to learn should have some knowledge or ability to learn that thing should have computer handling skills.

\section{Part 2: Attention}

The learner must have attention during the learning session. It refers to the active listening of the learner or student which will lead to grasp the lecture, dictation or learning material.

\section{Part 3: Air Pressure}

Understanding invisible and abstract attributes because air experts pressure and is made up of tiny particles (molecules) that are constantly moving (invisible process attributes). For air pressure, Student needs to understand the air particles (invisible attribute) exists pressure on all of sides of the system, including whatever is invisible system (Hsiao-Ching 2005). The more one pushes the system, the more air particles push again whatever is inside the system. 


\section{Part4: Learning from others}

Learning from others is an important part of the proposed model. Generally, it refers to the communication with others. Learning from other members depends upon the following two main factors:

- The level of communication adopted.

- Other's willingness to provide information.

The learning from others effect is mostly carried out through formal or informal communication among members of the same or different organizations (Deweett and Tons 2001).

\section{Conclusion}

Learning is the major topic of the HRD. The paper examines and investigates the literature review on employee learning and organizational learning in order to improve the performance. The key variables identifies related to the proposed learning model. There are so many learning models are developed by HRD researchers' e.g. Carroll's learning model, Kolb, Mayer, Lave, Gibson, and Burner's learning model etc. The paper presents the importance of the learning from feedback, strategic learning etc. The further discussion develops a proposed learning model which explains the key variables (Aptitude, Attention, Air pressure, learning from others, Feedback etc). The paper is divided into three parts. The introductory part provides brief overview related to learning and affect on performance. The second part analyzes the views and studies of the past researchers related to Learning models. In the end, paper presents the proposed model.

\section{References}

Adrianus de Kock, Peter Sleegers, Marinus J. M. Voeten (2004). New Learning and the Classification of Learning Environments in Secondary Education. Review of Educational Research, 74 (2), 141-170.

Anderson, L. M. (1989). Implementing instructional programs to promote meaningful, selfregulated learning. International Journal of Brophy( Ed.),A dvances in research on teaching, 1, 265-306). Greenwich C, T:J AI Press.

Argote, L. (1999). Organizational Learning: Creating, Retaining and Transferring Knowledge. Kluwer Academic Publishers, Boston, MA.

Blackwell, J. R., \& Newell, K. M. (1996). The informational role of knowledge of results in motor learning. Acta Psychologica, 92, 119-129. 
Pakistan Journal of Humanities and Social Sciences, 5(1), 2017

Brown, J. S., P. Duguid. (1991). Organizational learning and communities of practice: Toward a unified view of working, learning and innovation. Journal of Organizational Sciences, 2, 40-57.

Christopher, M. (2004). Learning From Feedback in Performance Measurement. Public Performance \& Management Review, 28(1), 9-29.

Deweett and Tons (2001). Culture and organizational learning. Journal of Management Inquiry, 2(4), 87-99.

Dixon, N. M. (1999). The organizational Learning Cycle: How we can Learn Collectively. Second Edition (4), Gower p. 63-91.

Fenwick, J. T (2001). Experiential Learning: A Theoretical Critique from Five Perspectives. ERIC Information Series No. 385.

Gagne, R . M. (1984). Learning outcomes and their effects:Useful categories of human performance. Journal of American Psychologist, 39(4), 377-385.

Gagne, R. M. (1985). The conditions of learning (4th ed.). New York: Holt, Rinehart \& Winston. (1st edition published in 1965).

Gibbs, G. (1988). Learning by doing: a guide to teaching and learning methods Further Education Unit, London (http:// www.glos.ac.uk/gdn/gibbs/index.htm) Accessed 30 July 2004 Hartman V F 1995 Teaching and learning style preferences:

Hsiao-Ching, (2005). Promoting Students' Learning of Air Pressure Concepts: The Interrelationship of Teaching Approaches and Student Learning Characteristics. The Journal of Experimental Education, 74(1), 29-51.

James B. Thomas, Stephanie Watts Sussman, John C. Henderson (2001). Understanding "Strategic Learning": Linking Organizational Learning, Knowledge Management, and Sense making. Journal of Organization Science, 12(3), 331-345.

Janice Nadler, Leigh Thompson, Leaf Van Boven ( 2003). Learning Negotiation Skills: Four Models of Knowledge Creation and Transfer. Journal of Management Science, 49(4), 529-540.

Kolb, D. A. (1983). Problem management: Learning from experience. In S. Srivastava et al. (Ed.), The Executive Mind.

Kolb, D. A. (1984). Experiential learning: Experience as the source of learning and development. Englewood Cliffs, NJ: Prentice-Hall.

Lave, J., \& Wenger, E. (1991). Situated learning: Legitimate peripheral participation. Cambridge UK: CambridgeU niversityP ress. 
Maurizio Zollo and Sidney G. Winter (2002). Deliberate Learning and the Evolution of Dynamic Capabilities, Journal of Organization Science, 13(3), Knowledge, Knowing, and Organizations pp. 339-351.

Pauline Kneale, John Bradbeer (2005). Learning Styles among Geography Undergraduates: An International Comparison Mick Healey,: Area, 37(1), 30-42.

Prem Ramburuth and John McCormick (2001). Learning Diversity in Higher Education: A Comparative Study of Asian International and Australian Students Journal of Higher Education, 42, 333-350.

Swanson, R.A. \& Holton, E.F. (2009). Foundations of Human Resource Development, Second Edition, San Francisco: Berrett-Koehler.

Thorndike, E. L. (1931). Human learning. New York: Century.

Van de Ven, A. H., D. Polley. (1992). Learning while innovating. Journal of Organizational Science, 1, 92-116.

Vermunt, I. and Minnaert, A. (2003). Dissonance in student learning patterns: when to revise theory? Studies in Higher Education, 28, 49-61.

Zander, U., B. Kogut. (1995). Knowledge and the speed of transfer and imitation of organizational capabilities: An empirical test. Journal of Organizational Sciences, 6, 76-92. 